OPEN ACCESS

Edited by:

Rong Hai,

University of California, Riverside,

United States

Reviewed by:

Duo Xu,

University of California, Riverside, United States

Guojun Wang,

Inner Mongolia University, China

*Correspondence: Dong-Sik Kim

dskim01@mogam.re.kr

${ }^{t}$ These authors have contributed equally to this work

Specialty section:

This article was submitted to Vaccines and Molecular Therapeutics, a section of the journal

Frontiers in Immunology

Received: 17 September 2021 Accepted: 27 October 2021 Published: 18 November 2021

Citation:

Lee S, Jang S, Kang J, Park SB, Han YW, Nam H, Kim M, Lee J, Cho KJ, Kim J, Oh M, Ryu J, Seok JH, Kim Y, Lee J-B, Park M-S, Kim Y-S, Park H and Kim D-S (2021) MG1141A

as a Highly Potent Monoclonal Neutralizing Antibody Against SARS-CoV-2 Variants.

Front. Immunol. 12:778829. doi: 10.3389/fimmu.2021.778829

\section{MG1141A as a Highly Potent Monoclonal Neutralizing Antibody Against SARS-CoV-2 Variants}

\author{
Sua Lee ${ }^{1 \dagger}$, Shina Jang ${ }^{1 \dagger}$, Jihoon Kang ${ }^{1}$, Soo Bin Park ${ }^{1}$, Young Woo Han ${ }^{2}$, Hyemi Nam ${ }^{3}$, \\ Munkyung $\mathrm{Kim}^{3}$, Jeewon Lee ${ }^{3}$, Ki Joon $\mathrm{Cho}^{1}$, Jeonghun Kim ${ }^{4}$, Miyoung Oh ${ }^{1}$, Jihye Ryu ${ }^{5}$, \\ Jong Hyeon Seok ${ }^{4}$, Yunhwa Kim ${ }^{6}$, Jee-Boong Lee ${ }^{3}$, Man-Seong Park ${ }^{4}$, Yong-Sung Kim ${ }^{7}$, \\ Hosun Park ${ }^{6}$ and Dong-Sik Kim ${ }^{1,7 *}$ \\ ${ }^{1}$ Department of Protein Engineering, Mogam Institute for Biomedical Research, Yongin, South Korea, ${ }^{2}$ Department of \\ Infectious Disease Research, Mogam Institute for Biomedical Research, Yongin, South Korea, ${ }^{3}$ Department of Target ID \& \\ Assay Development, Mogam Institute for Biomedical Research, Yongin, South Korea, ${ }^{4}$ Department of Microbiology, Institute \\ for Viral Diseases, Korea University College of Medicine, Seoul, South Korea, ${ }^{5}$ Department of Translational Research, \\ Mogam Institute for Biomedical Research, Yongin, South Korea, ${ }^{6}$ Department of Microbiology, College of Medicine, \\ Yeungnam University, Daegu, South Korea, ${ }^{7}$ Department of Molecular Science and Technology, Ajou University, \\ Suwon, South Korea
}

Since the coronavirus disease outbreak in 2019, several antibody therapeutics have been developed to treat severe acute respiratory syndrome coronavirus 2 (SARS-CoV-2) infections. Antibody therapeutics are effective in neutralizing the virus and reducing hospitalization in patients with mild and moderate infections. These therapeutics target the spike protein of SARS-CoV-2; however, emerging mutations in this protein reduce their efficiency. In this study, we developed a universal SARS-CoV-2 neutralizing antibody. We generated a humanized monoclonal antibody, MG1141A, against the receptorbinding domain of the spike protein through traditional mouse immunization. We confirmed that MG1141A could effectively neutralize live viruses, with an $E_{50}$ of 92 pM, and that it exhibited effective Fc-mediated functions. Additionally, it retained its neutralizing activity against the alpha (UK), beta (South Africa), and gamma (Brazil) variants of SARS-CoV-2. Taken together, our study contributes to the development of a novel antibody therapeutic approach, which can effectively combat emerging SARS-CoV2 mutations.

Keywords: MG1141A, SARS-CoV-2, monoclonal antibody, outbreak, spike protein

\section{INTRODUCTION}

The COVID-19 pandemic has caused more than 100 million infections and over 2 million deaths worldwide since its outbreak in 2019 (1). Not only has the pandemic caused incalculable damage to human health, but it has also impacted the world economically and socially. SARS-CoV-2, the causative agent of COVID-19, is a member of the beta-coronavirus family. Members of this family of viruses were also responsible for the SARS-CoV outbreak in 2004 and the MERS-CoV outbreak in 2015, which caused severe symptoms in patients. The sequence homology between SARS-CoV-2 and SARS-CoV and their spike (S) proteins is estimated to be $76 \%$ (2). The S protein is a 
glycoprotein that forms a homotrimeric structure, and its receptorbinding domain (RBD) binds to human angiotensin-converting enzyme 2 (ACE2), which regulates both cross-species and humanto-human transmissions of SARS-CoV (3). Therefore, $\mathrm{S}$ protein is the primary target for therapeutic agents and vaccines as it directly modulates host cell infection (4). Currently, antibody treatments, small molecules, and intravenous immunoglobulins are being developed as therapeutic agents to treat SARS-CoV infections; several antibody treatments are currently in clinical trials, and three of them have received emergency-use authorization from the FDA (5-7).

Antibody therapeutics exhibit several antiviral functions that are dependent on the antibody structure. Antibodies consist of two main structural regions: the Fab region binds to the target antigen, and the Fc region interacts with Fc-receptors on innate immune cells to mediate downstream effector functions. Therefore, antibodies block viral entry into host cells and enhance the clearance of viruses and infected cells through Fcmediated effector functions such as antibody-dependent cellular cytotoxicity (ADCC) or antibody-dependent cellular phagocytosis (ADCP). The antibody neutralizes SARS-CoV-2 by binding to the RBD of the viral $S$ protein and blocking its binding to the host cell receptor ACE2 (8-10). However, SARS$\mathrm{CoV}-2$ variants with $S$ protein mutations have recently emerged that exhibit enhanced transmission efficiency. The initial $S$ protein mutation was a D614G mutation in the G clade, which was reported in February 2020. The D614G mutation promoted the "standing-up" conformation of the RBD, wherein the key epitopes of the domain are more accessible, compared with those of wild type (WT) SARS-CoV-2 $(11,12)$. The affinity of the trimeric S protein toward ACE2 was slightly increased due to this mutation (13). In addition, the D614G mutation improved the stability of the $S$ protein, as well as replication and fitness of the virus (14). All the SARS-CoV-2 variants detected in 2021 possess the D614G mutation (15). Although the D614G mutation increases infectivity by altering the conformational state of the viral proteins, it does not reduce the efficacy of antibody therapy, immune antibodies, and vaccines in humans who have undergone treatment after an initial WT infection $(11,14,16)$. However, recent mutations, such as N501Y in the alpha variant (United Kingdom, lineage B.1.1.7), K417N, E484K, and N501Y in the beta variant (South Africa. B.1.351), and K417T, E484K, and N501Y in the gamma variant (Brazil, B.1.1.28), are located in the receptor-binding motif (RBM), which directly binds to ACE2 in RBD $(17,18)$. N501Y increases the affinity of RBD to ACE2 $(19,20)$, and $\mathrm{E} 484 \mathrm{~K}$, in particular, converts the charge on the flexible loop region of the RBD to form a new favorable contact point. As a result of the E484K mutation, N/T417 is in proximity to ACE2 and is expected to induce mutations in amino acids that can increase the binding strength to the receptor (21). These mutations increase the infectivity of the virus by increasing the affinity of SARS-CoV-2 toward ACE2. In addition, as the RBM is a major epitope to which a therapeutic neutralizing antibody binds, mutations in the RBM reduce the affinity of neutralizing antibodies, thereby reducing the neutralization efficiency (22). These mutations have also been reported to reduce the efficacy of vaccines currently under development (20, 23, 24). Accordingly, there is a need to develop therapeutic antibodies that are effective against SARS-CoV-2 variants in the future.

The use of antibody therapy is limited as it can only be used to treat patients with mild and moderate SARS-CoV-2 infections $(5,7,25,26)$. Although antibody therapy is effective in neutralizing the virus, it does not alleviate the inflammation that occurs in patients with severe infections (25). The inflammation caused by SARS-CoV-2 has not been clearly defined; an inflammatory signal is triggered by virus cleavage after the ACE2-expressing airway epithelial cells are infected by SARS-CoV-2. SARS-CoV-2 enters the target cell by binding to ACE2 via the RBD of its $\mathrm{S}$ protein, and human proteases act as entry activators. The viral membrane protein is expressed on target cells and activates inflammation-associated signaling pathways (27-29). Therefore, antibodies that exhibit a high Fcmediated effector function may effectively remove the virus and infected cells, thereby attenuating the progress of the disease.

In this study, we developed an antibody that effectively neutralizes the recently detected SARS-CoV-2 variants and has an efficacy equivalent to that of previously developed antibodies. Our results present new possibilities for antibody therapeutics using these novel antibodies.

\section{MATERIALS AND METHODS}

\section{Recombinant Protein Expression and Purification}

Genes encoding the ecto-domain (residues 13-1,202 aa) and the RBD (residues 319-541 aa) of the SARS-CoV-2 spike glycoprotein were synthesized and cloned into the pCIW mammalian expression vector with a C-terminal $6 \mathrm{x}$ histidine tag. Genes encoding RBD mono-Fc and human ACE2 mono-Fc [obtained from Prof. Jason S. McLellan, University of Texas (30)] were cloned into the pCIW vector. The pCIW mammalian vectors were transfected into Expi293F ${ }^{\mathrm{TM}}$ cells (Cat. no. A 1435101). All the steps for expression analysis were performed according to the manufacturer's instructions. After 5-6 days of cell cultivation, the cells were harvested by centrifugation, and the supernatant was passed through a 0.22 $\mu \mathrm{m}$ filter to remove cell debris. For His-tag purification of recombinant proteins, the Ni-NTA resin was added to the supernatant. MabSelect Xtra (Cat. no. 17-5269-02, GE Healthcare) was used as a resin for protein-A purification of Fc-fused proteins. All purification procedures were performed according to the manufacturer's instructions. The buffer of eluted proteins was changed with phosphate-buffered saline (PBS) using Zeba Spin Desalting Columns (Cat. no. 0089892). Protein concentration was quantified using a Nanodrop 2000C spectrophotometer (Thermo Scientific) and using SDS-PAGE under non-reducing and reducing conditions.

\section{Mouse Immunization}

Mouse immunization experiments were approved by the Institutional Animal Care and Use Committee of GC Pharma 
(\#GC-20-006A). Female BALB/c mice (Orientbio, Korea), aged 6 weeks, were immunized with an emulsion mixture of recombinant $100 \mu \mathrm{g}$ of RBD mono-Fc and complete adjuvant (Freund's Complete Adjuvant, Cat. no. F5881, Sigma-Aldrich). The mice were primed by intraperitoneal injection and administered booster doses on days 14 and 21. On days 28, 29, and 30 , the mice received final booster doses of $50 \mu \mathrm{g}$ of RBD mono-Fc without adjuvant via intravenous injection. On day 31 , splenocytes were harvested from the sacrificed mice to construct a phage display library. Immune sera were collected from the mice prior to each immunization, and antibody titers in the serum were evaluated by ELISA. Briefly, $100 \mathrm{ng}$ of RBD mono-Fc was coated onto 96-well ELISA plates and incubated at $4^{\circ} \mathrm{C}$ overnight. The next day, the plates were washed four times with $200 \mu \mathrm{L}$ of PBST $(0.05 \%$ Tween 20 in PBS) and blocked with 200 $\mu \mathrm{L}$ of $3 \%$ bovine serum albumin in PBS (BSA/PBS) for $1 \mathrm{~h}$ at room temperature (RT). The plates were then washed four times with PBST. Pre-immune and immune anti-sera isolated from mice at a $1: 10,000$ dilution in $3 \%$ BSA/PBS were added to the RBD mono-Fc coated plates and incubated for $1 \mathrm{~h}$ at RT. The plates were washed four times and antibody titers were detected using anti-mouse antibodies conjugated with horseradish peroxidase (HRP; Cat no. A0168, Sigma-Aldrich) and incubated for $1 \mathrm{~h}$ at RT. The plates were washed four times with PBST and developed with tetramethylbenzidine (TMB) solution $/ \mathrm{H}_{2} \mathrm{SO}_{4}$ stop solution (Cat. no. 50-76-03, KPL). Finally, the absorbance was measured at a wavelength of $450 \mathrm{~nm}$ on an ELISA plate reader (Perkin Elmer).

\section{Phage Display Library Construction}

Splenocytes were harvested from RBD-immunized mice. RNA extraction from fresh splenocytes was performed using the QIAGEN RNeasy Plus Mini Kit (Cat. no. 74104, Qiagen). cDNA was obtained by reverse transcription using the mRNA as a template (SuperScript IV first-strand synthesis system, Cat. no. 18090010, Invitrogen). The cDNA was then amplified and used in the 5' RACE system (Cat. no. 634858, Clonetech) (31). The cDNA library was constructed according to the manufacturer's instructions. The concentration of cDNA was quantified using a Qubit4 fluorometer (Thermo Scientific). To construct the phage $s c F v$ library, a heavy-chain variable domain and two variable domains of the light chain $\mathrm{V} \kappa$ and $V \lambda$ were amplified from cDNA using a mouse germline primer set (32). The amplified genes of heavy- and light-chain variable domains were adjusted to an equal molar ratio and used as templates with a linker $[(\mathrm{G} 4 \mathrm{~S}) 3]$ in an overlapping PCR reaction. The assembled $\mathrm{VH}-\mathrm{V \kappa} / \mathrm{V} \lambda$ vector was cloned into the pComb3XTT phagemid vector. Five vials of $1 \mu \mathrm{g}$ phagemid were transformed into Escherichia coli XL1-blue cells (electroporation-competent cells; Cat. no. 200228, Stratagene) separately at $2500 \mathrm{~V}$ with an electroporator (Bio-Rad). The size of the library was calculated from colony counting on plates by serial dilution.

\section{Phage Display Library Screening}

$\mathrm{RBD}$-His ( $1 \mu \mathrm{g}$ in PBS) was coated onto a polystyrene immunotube (No. 444202, Nunc) and incubated at $4^{\circ} \mathrm{C}$ overnight. The RBD-coated immuno-tubes were blocked with 3\% BSA/PBS at $37^{\circ} \mathrm{C}$ for $2 \mathrm{~h}$. The phage library $\left(10^{13} \mathrm{CFU} / \mathrm{mL}\right.$ in $\left.1 \% \mathrm{BSA} / \mathrm{PBS}\right)$ was then added to the tube and incubated at $37^{\circ} \mathrm{C}$ for $2 \mathrm{~h}$. The tube was washed 4-6 times with PBST, and then the bound phages in the immuno-tube were eluted with $1 \mathrm{~mL}$ of glycine$\mathrm{HCl}(\mathrm{pH} 1.5)$ at RT for $10 \mathrm{~min}$, and $150 \mu \mathrm{L}$ of $2 \mathrm{M}$ Tris- $\mathrm{Cl}(\mathrm{pH}$ 8.8) was immediately added for neutralization. The neutralized phages were mixed with $10 \mathrm{~mL}$ of XLI-Blue $\left(\mathrm{OD}_{600}=0.4\right)$ at RT for $30 \mathrm{~min}$. The infected cells were added to $90 \mathrm{~mL}$ of super broth (SB $35 \mathrm{~g} / \mathrm{L}$ tryptone, $20 \mathrm{~g} / \mathrm{L}$ yeast extract) containing $200 \mu \mathrm{L}$ of tetracycline $(50 \mathrm{mg} / \mathrm{mL}$ ) (Cat. no. E709-1, Amresco) and $100 \mu \mathrm{L}$ of carbenicillin (100 mg/mL carbenicillin; Cat. no. C1389, SigmaAldrich) and incubated with rotations at $220 \mathrm{rpm}$ at $37^{\circ} \mathrm{C}$ for $1 \mathrm{~h}$. The cells were infected with M13KO7 helper phage ( $>10^{11} \mathrm{pfu} /$ $\mathrm{mL}$; Cat. no. N0315S, NEB) and incubated at $220 \mathrm{rpm}$ at $37^{\circ} \mathrm{C}$ for $1 \mathrm{~h}$. The cells were treated with $100 \%$ kanamycin $(50 \mathrm{mg} / \mathrm{mL}$; Cat. no. E713-1, Amresco) and cultured overnight at $37^{\circ} \mathrm{C}$ and $220 \mathrm{rpm}$. The next day, for the rescue phage library, the supernatant was harvested by centrifugation at $6,000 \mathrm{rpm}$ for $15 \mathrm{~min}$. Next, $5 \mathrm{X}$ polyethylene glycol/ $\mathrm{NaCl}$ was added to the supernatant at a $1 \times$ dilution and incubated on ice for $1 \mathrm{~h}$. The supernatant was discarded after centrifugation. The precipitate was resuspended in $1 \%$ BSA/PBS, and the supernatant was harvested by centrifugation and used in the subsequent panning process. The procedure described above was repeated three times. Single colonies were randomly collected from the third round of panning the library and inoculated into a deep 96well culture plate, followed by overnight cultivation. Harvested cells in the plate were stored at $-70^{\circ} \mathrm{C}$ for further use. The supernatant of the single clones was bound to RBD-coated ELISA plates. Finally, the plates were read on an ELISA plate reader (Perkin Elmer), and clones with high OD values were selected as positive clones for sequencing.

\section{Antibody Expression and Purification}

Anti-SARS-CoV-2 scFvs were converted into the human IgG1 format by subcloning into pCIW. Expi293F cells were prepared in $30 \mathrm{~mL}$ of Expi293 expression medium (Cat. no. A1435101, Gibco) at a concentration of $2.5 \times 10^{6}$ cells $/ \mathrm{mL}\left(37^{\circ} \mathrm{C}, 8 \% \mathrm{CO}_{2}\right.$, $125 \mathrm{rpm}$, viability $\geq 95 \%)$. These cells were transfected with a DNA mixture composed of $30 \mu \mathrm{g}$ of DNA (pCLW-anti-SARSCoV-2 heavy chain: $15 \mu \mathrm{g}$, pcIw-anti-SARS-CoV-2 light chain: $15 \mu \mathrm{g}$ ), OptiPro SEM medium (Cat. no. 12309019, Gibco), and ExpiFectamine 293 reagent (Cat. no. A14524, Gibco). Cultivation and protein-A purification were performed as described previously.

\section{Competition ELISA Assay}

For ELISA, $30 \mathrm{nM}$ of ACE2 mono-Fc was coated per well on a 96well ELISA plate and incubated at $4^{\circ} \mathrm{C}$ overnight. The next day, the wells were blocked with 3\% BSA/PBS for $1 \mathrm{~h}$, and the mixture of spike protein and antibodies was added and incubated for $1 \mathrm{~h}$ at RT. The mixture was mixed with the spike protein $(10 \mathrm{nM})$ and antibodies (at a concentration ranging from $0.5 \mathrm{pM}$ to $500 \mathrm{nM}$ ). Plates were washed with $0.05 \%$ PBST and rabbit anti-SARS-CoV-2 spike antibody (Cat. no. 40589-T62, Sino Biological) was added at a 1/1,000 dilution. After $1 \mathrm{~h}$ of incubation at RT, the plates were washed with $0.05 \%$ PBST and goat anti-rabbit IgG-HRP (Cat. no. 
31460, Invitrogen) was used as a secondary antibody. After $1 \mathrm{~h}$ of incubation, the plates were washed with $0.05 \%$ PBST. After 5 min of incubation with $50 \mu \mathrm{L}$ TMB solution, $50 \mu \mathrm{L}$ of stop solution was added. Absorbance was measured at $405 \mathrm{~nm}$. The experiments were performed in triplicates.

\section{Antibody Binding Kinetics of Antibodies Toward S Protein}

The binding kinetics of anti-S protein antibodies were determined using a Biacore T-200 biosensor (Cytiva). The antibodies were diluted with HBS-EP buffer (Cat. no. BR100826, Cytiva) (running buffer) to make up a concentration of $10 \mu \mathrm{g} / \mathrm{mL}$ and captured at a flow rate of $10 \mu \mathrm{L} / \mathrm{min}$ until Rmax reached $200 \mathrm{Ru}$ on an SA chip (Cat. no. BR100530, Cytiva). S protein serially diluted in HBS-EP buffer was run on the antibody-captured SA chip at a concentration of $0.3125-20 \mathrm{nM}$ at a flow rate of $30 \mu \mathrm{L} / \mathrm{min}$ for $3 \mathrm{~min}$ for association and $30 \mathrm{~min}$ for dissociation. Next, $10 \mathrm{mM}$ glycine- $\mathrm{HCl}(\mathrm{pH} 1.5)$ (Cat. no. BR100354, Cytiva) was run for $30 \mathrm{~s}$ to wash the $\mathrm{S}$ protein that was bound to the antibody. A sensorgram of antibodies was analyzed using Biacore evaluation software, and the value in the analysis concentration range that had the lowest chi-square value was selected. Four or more concentrations were selected at this time.

\section{Antibody Binding Analysis Against RBD Variants}

Antibody binding affinity for alpha (UK, Cat. no. 40592-V08H82, Sino Biological), beta (South Africa, Cat. no. 40592-V08H85, Sino Biological), and gamma (Brazil, Cat. no. 40592-V08H86, Sino Biological) (Supplementary Table 1) variants were measured using octet QKe. RBD variants $(5 \mu \mathrm{g} / \mathrm{mL})$ were immobilized on the Ni-NTA biosensor for $150 \mathrm{~s}$ and reacted with $0.031-125 \mathrm{nM}$ antibody for $150 \mathrm{~s}$. The reacted biosensors were dipped into the dissociation well and dissociation was recorded for $300 \mathrm{~s}$. The association and dissociation steps were analyzed using data analysis software. Background correction was performed using a reference biosensor in which the antibody was not bound. The analysis model was set to a 1:1 binding model, and fitting data were secured by global fitting.

\section{Pseudovirus Production}

Pseudoviruses bearing the full-length spike protein of SARS-CoV-2 and variants carrying a firefly luciferase reporter gene were produced in Lenti-X 293T cells (Cat. no. 632160, Takara). Briefly, $10 \mu \mathrm{g}$ of psPAX2 (plasmid no. 12260, Addgene), $10 \mu \mathrm{g}$ of pLVXLuciferase and $10 \mu \mathrm{g}$ of SARS-CoV-2 S (codon-optimized) expression plasmids were co-transfected with polyethylenimine (mass ratio of 1:2) (Cat. no. 23966, Polysciences) in Lenti-X $293 \mathrm{~T}$ cells. At $72 \mathrm{~h}$ post-transfection, the supernatant was centrifuged for $15 \mathrm{~min}$ at $2200 \mathrm{rpm}$ followed by filtration via 0.45 $\mu \mathrm{m}$ filters and stored at $-70^{\circ} \mathrm{C}$ for further use. Pseudovirus titers were determined by measuring the relative luciferase units.

\section{Neutralization Assay With SARS- CoV-2 Pseudovirus}

The ACE2-HEK293 stable cell line (Cat. no. M00770, Genscript) was maintained in Dulbecco's modified Eagle medium (DMEM;
Cat. no. 11995-065, Gibco) supplemented with 10\% heatinactivated fetal bovine serum (FBS; Cat. no. 16000-044, Gibco), an antibiotic-antimycotic cocktail (Cat. no. 15240, Gibco), and $2 \mathrm{mg} / \mathrm{mL}$ hygromycin B (Cat. no. 10687010, Thermo Fisher Scientific). A 96-well flat bottom plate (Cat. no. 167008, Thermo Scientific Nunc) was coated with $10 \mu \mathrm{g} / \mathrm{mL}$ collagen I (Cat. no. A1048301, Thermo Fisher Scientific) and incubated at $37^{\circ} \mathrm{C}$ in an atmosphere containing $5 \% \mathrm{CO}_{2}$ for $4 \mathrm{~h}$. ACE2-HEK293 cells were inoculated into a collagen-coated 96well flat bottom plate at $1 \times 10^{5}$ cells/well in DMEM (Cat. no. 11995-065, Gibco), in which 10\% heat-inactivated FBS and antibiotic-antimycotic cocktail was added $24 \mathrm{~h}$ prior to the assay. Antibodies were serially diluted 3-fold with DMEM containing 2\% heat-inactivated FBS and antibiotic-antimycotic cocktail (this will be referred to as 'infectious media'), for an 11point dilution curve in the assay beginning at $10 \mu \mathrm{g} / \mathrm{mL}(66.67$ $\mathrm{nM})$. SARS-CoV-2 pseudoviruses were diluted $1: 10$ in the infectious media. Antibody dilutions were mixed 1:1 with 1/10 diluted pseudovirus and incubated at $37^{\circ} \mathrm{C}$ in an atmosphere containing $5 \% \mathrm{CO}_{2}$ for $1 \mathrm{~h}$. The supernatant was removed from ACE2-HEK293 cells and replaced with $50 \mu \mathrm{L}$ of antibodypseudovirus mixture. The cells were then incubated at $37^{\circ} \mathrm{C}$ in an atmosphere containing $5 \% \mathrm{CO}_{2}$ for $1 \mathrm{~h}$. Fifty microliters of infectious media was added to the cells, and the cells were further incubated at $37^{\circ} \mathrm{C}$ in an atmosphere containing $5 \% \mathrm{CO}_{2}$ for $48 \mathrm{~h}$. The cells were lysed with 5X reporter lysis buffer (Cat. no. L3971, Promega) and relative luciferase activity was determined using a luciferase assay system (Cat. no. E1501, Promega) and a luminometer (Cat. no. GM2010, Promega). Relative luciferase units were converted to percent neutralization and plotted with a non-linear regression curve fit in Prism Software (GraphPad, Prism 8.0).

\section{Plaque Assay}

A plaque assay was performed using Vero cells to quantify infectious virions. Briefly, we infected Vero cells with 10-fold serial dilutions of $\mathrm{GH}$ clade virus (BetaCoV/South Korea/ $\mathrm{KUMC} 45 / 2020$ ) isolated from a patient's plasma at $37^{\circ} \mathrm{C}$ in $5 \%$ $\mathrm{CO}_{2}$ for $1 \mathrm{~h}$. Subsequently, the cells were washed three times with PBS after infection, and then $2 \mathrm{~mL}$ of an overlay medium was added. The overlay medium was composed of $2 \%$ agar and $1 \mu \mathrm{g} /$ mL 1-(tosylamido-2-phenyl) ethyl chloromethyl ketone (TPCK)treated trypsin (Cat. no. 857254, Sigma-Aldrich). The infected cells were stained with crystal violet to count the number of plaques after $72 \mathrm{~h}$.

\section{Authentic SARS-CoV-2 Plaque Reduction Neutralization Test (PRNT)}

Monoclonal antibodies that were serially diluted two-fold were mixed with an equal amount of virus suspension containing 100 plaque-forming units at $37^{\circ} \mathrm{C}$ for $1 \mathrm{~h}$. The virus-antibody mixtures were inoculated into Vero cells to measure the $\mathrm{PRNT}_{50}$. The PRNT 50 titer was calculated as the highest serum dilution that showed a $50 \%$ reduction in the number of viral plaques in comparison with that of a PBS-treated control. To compare with $\mathrm{PRNT}_{50}$ titer, neutralizing dilution $\left(\mathrm{ND}_{50}\right)$ titer 
was determined as well, which was calculated using the Spearman-Karber formula.

\section{Generation of a Cell Line That Expresses the Spike Protein of SARS-CoV-2}

To generate a stable cell line that expresses the spike protein of SARS-CoV-2 (HT1080-S), the pcDNA3.1-spike protein of SARS-CoV-2 was transfected into HT1080 cells using Lipofectamine 3000 Transfection Reagent (Cat. no. L3000075, Invitrogen), and the transformants expressing SARS-CoV-2 S protein were selected with $1.5 \mathrm{mg} / \mathrm{mL}$ geneticin (Cat. no. 10131035, Gibco). The expression of SARS-CoV-2 S protein was confirmed using flow cytometry (FACS LSR Fortessa, BD Biosciences) using REGN10933, an anti-SARS-CoV-2 antibody.

\section{Measurement of Fc-Mediated Effector Functions}

For the ADCC assay, HT1080-S cells served as target cells and Jurkat-NFAT-Luc/FcyRIIIa served as effector cells. They were incubated with titrated concentrations of antibodies for $15 \mathrm{~min}$ (Cat. no. G7018, Promega) (E:T ratio $=10: 1)$. After incubation at $37^{\circ} \mathrm{C}$ in an atmosphere containing $5 \% \mathrm{CO}_{2}$ for $6 \mathrm{~h}$, Bio-Glo luciferase assay reagent was added, and luminescence was measured according to the manufacturer's instructions. For the ADCP assay, HT1080-S cells were incubated with titrated concentrations of antibodies for $15 \mathrm{~min}$ and Jurkat-NFAT-Luc/ Fc $\gamma$ RIIa-H cells (Cat. no. G9995, Promega) were added as effector cells $(\mathrm{E}: \mathrm{T}$ ratio $=5: 1)$. Incubation and luminescence measurements were performed as described previously.

\section{Epitope Binning}

Epitope binning was performed in three steps using the BLI system (Octet Qke): step 1 involved antigen immobilization, step 2 involved $1^{\text {st }}$ antibody binding, and step 3 involved $2^{\text {nd }}$ antibody binding. Between each step, a baseline step with a duration of $60 \mathrm{~s}$ was set to check the baseline signal. In step $1,20 \mu \mathrm{g} / \mathrm{mL}$ purified recombinant SARS-CoV-2 Spike protein RBD-His was immobilized in a prehydrated anti-penta-His biosensor at 1,000 rpm for $200 \mathrm{~s}$. In step $2,37.5 \mu \mathrm{g} / \mathrm{mL}$ of different $1^{\text {st }}$ binding Abs were bound for $300 \mathrm{~s}$. In step 3, one type of the $2^{\text {nd }}$ antibody $(18.75 \mu \mathrm{g} / \mathrm{mL})$ was bound for $150 \mathrm{~s}$ to check the degree of self-binding and competition. The degree of competition was defined as a percentage. The case in which only the $2^{\text {nd }}$ antibody was bound to the immobilized antigen was defined as $100 \%$. Relative to this reference, a binding level of $<33 \%$ was defined as complete competition, the level between $33 \%$ and $66 \%$ was defined as intermediate competition, and a level of $>66 \%$ was defined as non-competition. Similar experiments were conducted to confirm competitive binding of the ACE2 receptor. The difference was that the binding affinity of the recombinant human ACE2 receptor and the recombinant SARS-CoV-2 spike protein RBD was about 10-100 compared with the affinity between $\mathrm{mAb}$ and $\mathrm{RBD}$; thus, the ACE2 receptor was only used for step 3 , which involved the $2^{\text {nd }}$ antibody binding.

\section{Simulation Docking}

BioLuminate within Schrödinger Suite was used for scFv homology modeling of MG1141A using the structure of anti-PD1 (PDB code:
6JJP) and anti-SIRP $\alpha$ antibodies (PDB code: $6 \mathrm{NMR}$ ) as templates for heavy and light chains, respectively (33). Model quality was assessed using a Ramachandran plot and protein report. Docking of scFv structures of MG1141A to RBD (PDB code: 6M0J) was performed using PIPER in BioLuminate (34). The distances between Lys440 and Thr500 of RBD and complementaritydetermining region (CDR) loops were constrained between $2 \AA$ and $10 \AA$ based on the results of epitope binning. BioLuminate suggested 30 best complexes with 70,000 possible protein-protein configurations. The final complexes for MG1141A were selected according to the cluster size and agreement with the epitope binning results; then, energy minimization was performed.

\section{RESULTS}

\section{Mouse Immunization and Selection of Anti-RBD Antibodies}

To prepare soluble antigens for antibody screening, the RBD of SARS-CoV-2 S protein (residues 319-541 aa) and human ACE2 fused to C-terminal human monomeric-Fc (30), named RBD-Fc and ACE2-Fc, respectively, were expressed in Expi293F cells. RBD linked with $6 \mathrm{x}$-His tags at the C-terminal, referred to as RBD-His, was expressed in Expi293F cells. RBD-Fc and ACE2-Fc were purified using a protein-A column. RBD-His was purified using a $\mathrm{Ni}$-NTA column. The size and purity of the purified protein were confirmed by SDS-PAGE under reducing and non-reducing conditions (Figure 1A). To generate anti-SARS-CoV-2 RBD antibodies, four female $\mathrm{BALB} / \mathrm{c}$ mice were immunized with purified RBD-Fc (Figure 1B). Recombinant RBD-Fc was expected to be more stable than RBD-His; the C-terminus was masked so that antibodies specific to the region proximal to RBM are generated. However, in mouse immunization, human FC antibodies are highly likely to be generated. In order to select mice with enhanced generation of antibodies against the RBD, we evaluated antibody titers in serum samples by ELISA against RBDHis after immunization. Only one mouse exhibited enhanced antiRBD antibody production, whereas the others generated primarily anti-human Fc antibodies. Note that $\sim 1.67 \times 10^{8}$ splenocytes were harvested after sacrificing the mouse. The cDNA corresponding to the antibody variable domain was synthesized from the total RNA of splenocytes with $5^{\prime} \mathrm{RACE}$ and mouse germline primer sets (31, 32 ). Mouse single-chain variable fragment ( $\mathrm{scFv}$ ) phage display libraries were constructed for kappa and lambda chains with a diversity of $\sim 6.0 \times 10^{7}$. After three rounds of immuno-tube panning with RBD-His, RBD scFv binders were generated. The $\mathrm{RBD}$ binders were converted into the human IgG1 format and expressed in Expi293F cells. The mouse/human chimeric antibodies, named M4, were selected by binding analysis against the $S$ protein and a pseudovirus neutralization assay (Figures 1C, D).

\section{Generation of Humanized Antibody by CDR Grafting}

The framework region sequences of the M4 mouse antibody were identified using the mouse germline sequences IGHV5-6 and IGKV6-32. For the humanization of M4, CDR grafting was 


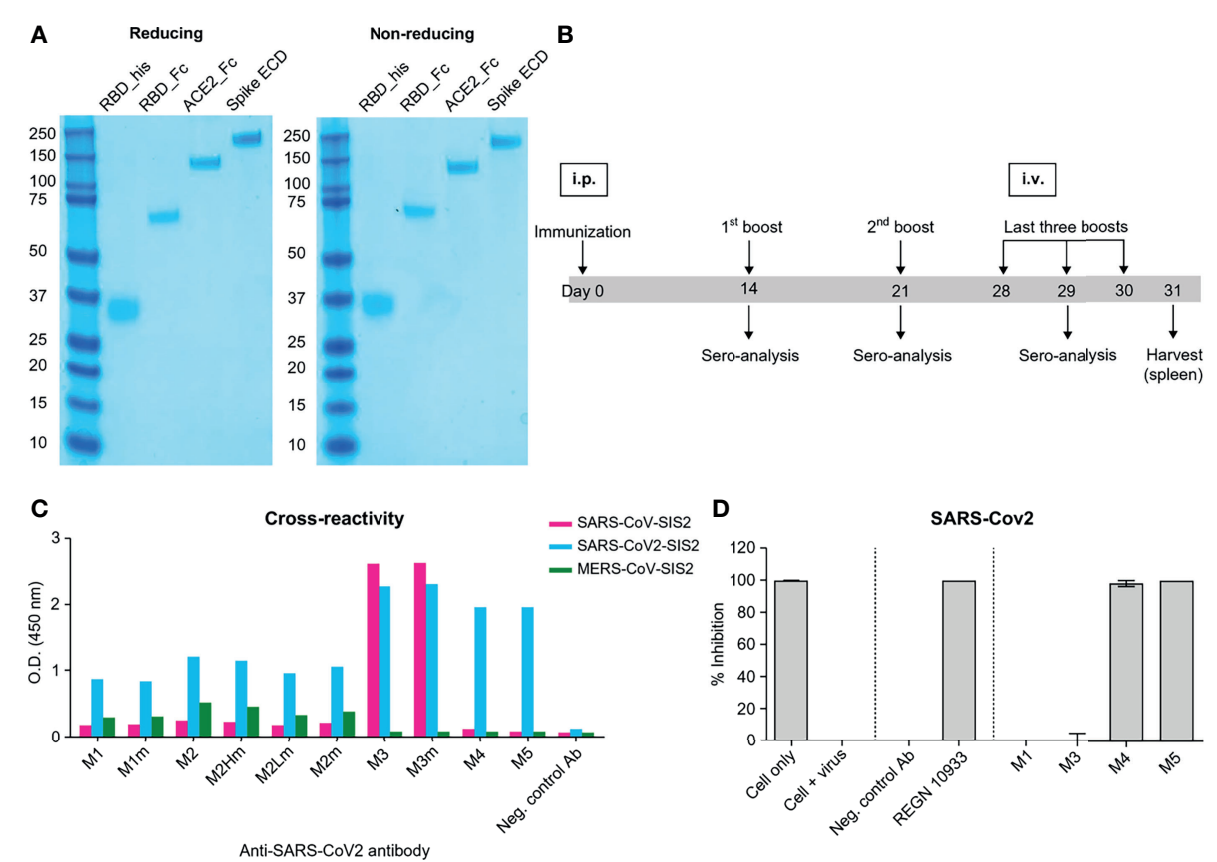

FIGURE 1 | Mouse immunization and in vitro screening of anti-SAR-CoV-2 chimeric mAbs. (A) SDS-PAGE of recombinant proteins purified from Expi293F cells. SDS-PAGE was performed in reducing (left) and non-reducing conditions (right). All the proteins were expressed as monomers; the same band patterns were observed in both conditions. (B) A schematic of the mouse immunization protocol. Immunization, $1^{\text {st }}$, and $2^{\text {nd }}$ booster doses were administered by intraperitoneal injections of $100 \mu \mathrm{g}$ of RBD mono-Fc. Last three booster doses were injected intravenously with $50 \mu \mathrm{g}$ of RBD mono-Fc. (C) Binding analysis of chimeric mAbs against beta-coronavirus spike proteins. M3, M4, and M5 clones significantly bind to the SARS-CoV-2 spike protein. The M3 clone was cross-reactive to both SARS-CoV and SAR-CoV-2. (D) Inhibition screening against SARS-CoV-2 pseudovirus for chimeric mAbs. Each mAb was tested by luciferase assay system. The inhibition of SARS-CoV-2 pseudovirus by the antibodies in human ACE2-overexpressed HEK293 cells was measured in luciferase units. Anti-CEACAM1 antibody is the isotype control.

performed $(35,36)$. The human frameworks IGHV3-21 and IGKV3-15 were identified using an IgBLAST search, and the sequences that were highly homologous to those of $\mathrm{M} 4, \mathrm{VH}$, and VL were selected. IGHV3 and IG $\kappa V 3$ are favorable germline pairs among the repertoire of antibodies $(37,38)$. A simple transfer of the CDR sequence in the humanization process is not sufficient, as preservation of core residues is critical to retaining the biophysical properties of the humanized antibody. The upper core residues indirectly affect the CDR conformation. Residues of the lower and central core and the charged clusters contribute to the overall stability of the antibody $(39,40)$. Most of the core-residue sequences were identical between mice and humans. Only four residues of the light chain had different sequences; however, the residues exhibited similar characteristics, with no additional mutations (Supplementary Figure 1). Humanized M4 was converted into the human IgG1 format and expressed in Expi293F cells. After purification with a protein-A column, the size and purity of humanized M4 IgG were confirmed by SDSPAGE (Supplementary Figure 2). The constructed humanized M4 antibody was named MG1141A.

\section{Binding Characterization of the Humanized Antibody}

The affinity of the M4 and MG1141A clones was determined by surface plasmon resonance (SPR Biacore T-200). M4 and its humanized form, MG1141A IgGs, bound to the S protein extracellular domain (ECD) of SARS-CoV-2 with a binding affinity of $1.997 \times 10^{-11} \mathrm{M}$ and $<1.0 \times 10^{-12} \mathrm{M}$, respectively (Figures 2A, B). After humanization, MG1141A exhibited an enhanced dissociation rate (10-fold higher) compared with M4. We evaluated the binding affinity of the mAbs as compared with the potent neutralizing mAbs used in clinical trials such as REGN10933 and REGN10987 of Regeneron Pharmaceuticals and S309 of GSK/Vir (the parent of VIR-7831). The abovementioned mAbs bound to the same antigen with a binding affinity of $3.195 \times 10^{-11} \mathrm{M}, 1.744 \times 10^{-11} \mathrm{M}$, and < $1.0 \times 10^{-12} \mathrm{M}$, respectively (Supplementary Figure 3 ). Their binding affinity data were as reported in previously published studies $(41,42)$.

Next, we evaluated the binding of the mAbs against the RBD of alpha (United Kingdom), beta (South Africa), and gamma (Brazil) variants. In this experiment, M4, MG1141A, REGN10933, REGN10987, and REGN cocktail (REGN10933 + 10987, 1:1 mix) antibodies were used. The REGN cocktail was used to compare whether two antibodies with different RBM epitopes were synergistic in their action against variants when used as a mixture $(41,43)$. As determined by biolayer interferometry assay, REGN10933, an RBM-targeting neutralizing antibody, exhibited a similar binding affinity for the alpha variant as it did for the WT. However, we observed that the 

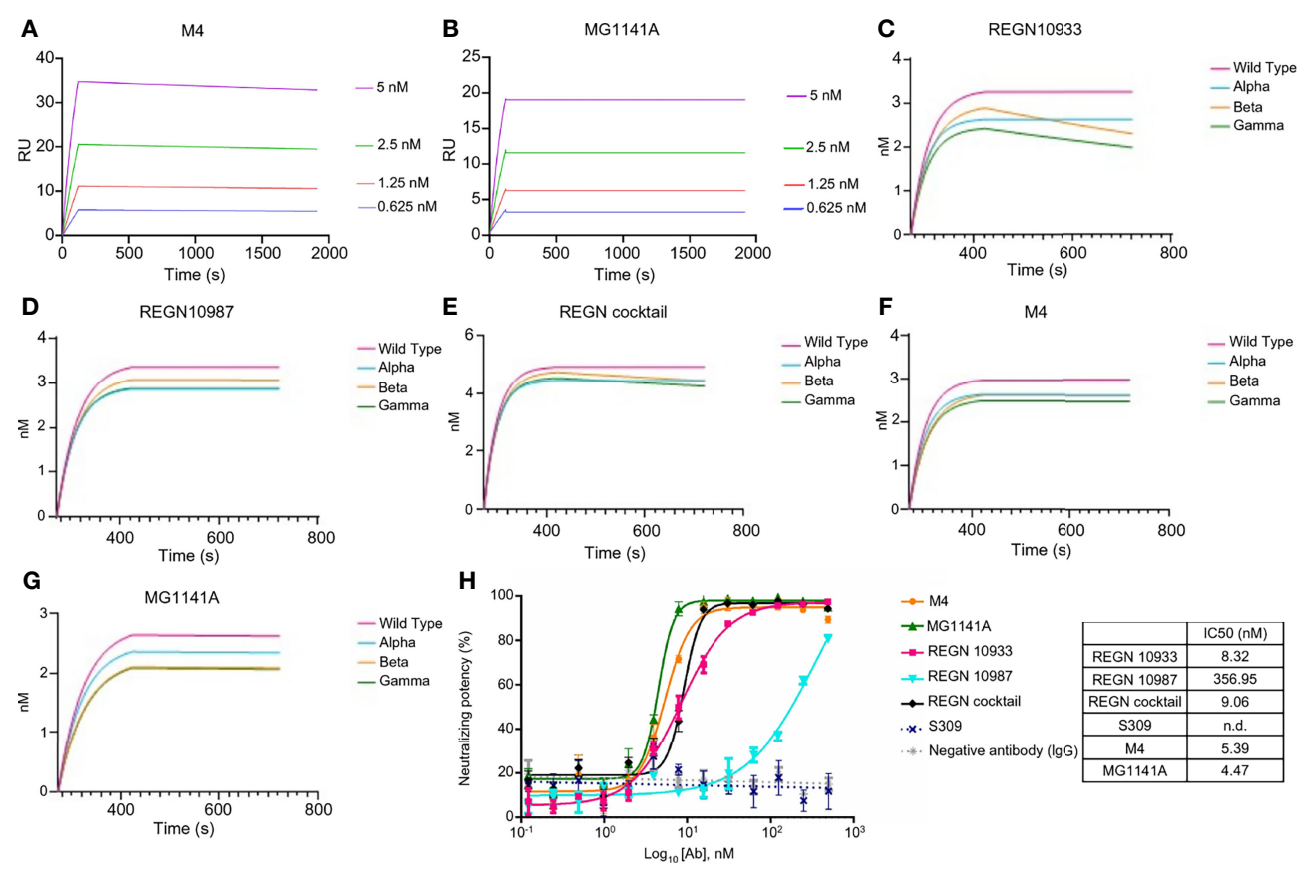

FIGURE 2 | Binding properties of anti-SARS-CoV-2 mAbs. (A, B) Binding sensorgrams of SARS-CoV-2 mAbs. Binding analysis of mAbs on a protein-A chip at $25^{\circ} \mathrm{C}$ using Biacore T-200. S protein was serially diluted (2-fold) from $0.3125 \mathrm{nM}$ to $20 \mathrm{nM}$ and was run on the chip for $180 \mathrm{~s}$ for association and 1,800 s for dissociation. Equilibrium dissociation constants $\left(k_{D}\right)$ were calculated from $k_{\text {off }} / k_{\text {on }}$; at least four concentrations of $S$ proteins were used. (C-G) Binding sensorgram of SARS-CoV-2 mAbs against SARS-CoV-2 proteins of alpha (United Kingdom), beta (South Africa), and gamma (Brazil) variants. Binding analysis of RBD variant captured on a Ni-NTA chip using an Octet Qke instrument. SARS-CoV-2 mAbs (125 nM) were run on the chip for $150 \mathrm{~s}$ for association and $300 \mathrm{~s}$ for dissociation. One representative graph out of two experiments that showed similar results is shown. (H) Competitive ELISA of mAbs with RBD against ACE2. Human ACE2 was coated on the ELISA plate, followed by incubation with a pre-incubated mixture of mAbs and RBD at $4^{\circ} \mathrm{C}$ overnight. The results are represented as a non-linear regression line, fitted by GraphPad Prism 6. The competition of all mAbs was observed, except for S309; the results are represented by dots.

binding of REGN10933 to beta and gamma variants was significantly reduced. These results are consistent with previously published data and reconfirmed that mutations in the K417 and E484 residues, which contribute toward the binding of REGN10933 to the RBD, are responsible for the reduced binding. Another RBM-targeting neutralizing antibody, REGN10987, exhibited similar binding affinities with the WT and all the variants. It is possible that the variant used in this test did not harbor the residues K444 or V445, which play an important role in the binding of REGN10987 to the RBD. In contrast, M4 and MG1141A showed no change in binding to the variants. These results suggest that our antibodies may retain their ability to bind to newly generated SARS-CoV-2 variants (Figures 2C-G). We further evaluated the ability of the antibody to inhibit the binding between the RBD of SARS-CoV-2 and human ACE2. We incubated the RBD with increasing concentrations of each antibody at $4^{\circ} \mathrm{C}$ overnight and measured its binding to $\mathrm{ACE} 2$ at $37^{\circ} \mathrm{C}$. The binding of the $\mathrm{RBD}$ with ACE2 was effectively inhibited with an $\mathrm{IC}_{50}$ at the single-digit nanomolar level by M4, MG1141A, and Regeneron antibodies except S309 (Figure 2H). Thus, our antibodies had an extremely high affinity for the $\mathrm{S}$ protein and effectively competed with ACE2. Consequently, we expect our antibodies to have high neutralizing potency against SARS-CoV-2.

\section{MG1141A Exhibits Comparable Neutralizing Efficacy Against SARS-CoV-2 WT and Variants}

We performed authentic virus and pseudovirus neutralization assays using a lentiviral system expressing the SARS-CoV-2 spike proteins and SARS-CoV-2 receptor-expressing ACE2-HEK293 stable cell line (Supplementary Figure 4A). MG1141A $\left(\mathrm{EC}_{50}=\right.$ $0.249 \mathrm{nM}, 95 \%$ confidence interval [CI] 0.150-0.412) showed a neutralizing efficacy similar to that of the original clone, M4 $\left(\mathrm{EC}_{50}=0.313 \mathrm{nM}, 95 \% \mathrm{CI} 0.142-0.688\right)$. The neutralization potency was comparable to that of single Regeneron antibodies $\left(\mathrm{REGN} 10933, \mathrm{EC}_{50}=0.154 \mathrm{nM}, 95 \% \mathrm{CI} 0.077-0.307\right.$ or REGN10987, $\mathrm{EC}_{50}=0.130 \mathrm{nM}, 95 \%$ CI $\left.0.085-0.198\right)$ or a cocktail $\left(\mathrm{EC}_{50}=0.157 \mathrm{nM}, 95 \%\right.$ CI $\left.0.087-0.283\right)$ of Regeneron antibodies against D614G (WT) pseudovirus (Figure 3A). Next, to assess the neutralizing efficacy of MG1141A against SARSCoV-2 spike variants, alpha (United Kingdom), beta (South Africa), and gamma (Brazil) pseudovirus neutralization assays were performed using a lentiviral system expressing each SARSCoV-2 spike variant (Supplementary Figure 5). M4 and MG1141A were able to neutralize three variant pseudoviruses with a neutralizing efficacy comparable to that of REGN10987 or Regeneron cocktail (Figures 3B-D). REGN10933 failed to mediate $100 \%$ neutralization of beta or gamma variant 
pseudovirus infection in cells even at high concentrations (Figures 3C, D). Taken together, our humanized SARS-CoV-2 antibody candidate, MG1141A, potently neutralized WT and selected spike-mutant SARS-CoV-2 pseudovirus particles, and its neutralizing efficacy is comparable to that of the Regeneron cocktail. We determined both the $\mathrm{EC}_{50}$ and $\mathrm{EC}_{90}$ values of MG1141A against clinical SARS-CoV-2 isolates (Korea/KUMC45/2020, clade GH) by the PRNT. M4 and MG1141A showed neutralization potency against the authentic virus with $\mathrm{EC}_{50}$ values of $0.083 \mathrm{nM}(95 \% \mathrm{CI}$ $0.053-0.121)$ and $0.092 \mathrm{nM}(95 \%$ CI $0.059-0.137)$, respectively. Moreover, MG1141A showed strong neutralizing activity, with an $\mathrm{EC}_{90}$ value of $0.559 \mathrm{nM}$ (95\% CI 0.251-1.202), which was comparable to that of the Regeneron cocktail $\left(\mathrm{EC}_{90}=0.346 \mathrm{nM}\right.$, 95\% CI 0.169-0.685) (Figure 3E). The $\mathrm{EC}_{50}$ values of the in vitro neutralizing assay of anti-SARS-CoV-2 mAbs against variant viruses (Figure 3F).

\section{MG1141A Has the Potential to Induce Fc- Mediated Antibody Effector Functions}

The neutralizing antibody mediates additional antiviral functions to accelerate the clearance of virus particles and infected cells through $\mathrm{Fc}$ gamma receptor $(\mathrm{Fc} \gamma \mathrm{R})$-mediated effector functions such as ADCC and ADCP (44-46). To assess the Fc receptordependent function of anti-SARS-CoV-2 antibody candidates, ADCC and ADCP assays were performed in Jurkat reporter cells and SARS-CoV-2 S protein-expressing HT1080 target cells (Supplementary Figure 4B). We found that MG1141A $\left(\mathrm{EC}_{50}=\right.$ $0.943 \mathrm{nM}, 95 \%$ CI $0.514-1.728$ ) induced ADCC activity against SARS-CoV-2 S protein-expressing targets higher than that of the original mouse clone M4 (EC $\mathrm{E}_{50}=3.376 \mathrm{nM}, 95 \%$ CI 2.060-5.532) and similar to that of the single Regeneron antibody (REGN10933, $\mathrm{EC}_{50}=0.643 \mathrm{nM}, 95 \%$ CI $0.382-1.083$ or REGN10987, $\mathrm{EC}_{50}=0.750$ $\mathrm{nM}, 95 \%$ CI $0.427-1.317)$ or cocktail $\left(\mathrm{EC}_{50}=0.406 \mathrm{nM}, 95 \% \mathrm{CI}\right.$ 0.264-0.625) of Regeneron antibodies (Figure 4A). MG1141A induced ADCP activity $\left(\mathrm{EC}_{50}=2.644 \mathrm{nM}, 95 \%\right.$ CI 1.208-5.786) comparable to that of a single Regeneron antibody (REGN10933, $\mathrm{EC}_{50}=2.112 \mathrm{nM}, 95 \%$ CI $0.519-8.595$ or REGN10987, $\mathrm{EC}_{50}=1.949$ $\mathrm{nM}, 95 \%$ CI $0.663-5.730)$ or a cocktail $\left(\mathrm{EC}_{50}=1.353 \mathrm{nM}, 95 \% \mathrm{CI}\right.$ 0.792-2.309) of Regeneron antibodies (Figure 4B). Collectively, the data in Figure 4 show that MG1141A has the potential to induce the Fc-mediated antibody effector functions, ADCC and ADCP, to mediate maximal therapeutic efficacy.
A

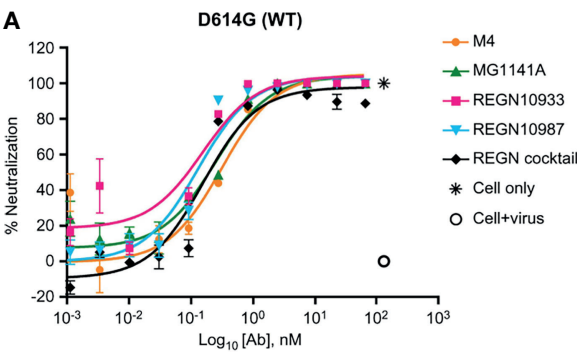

C

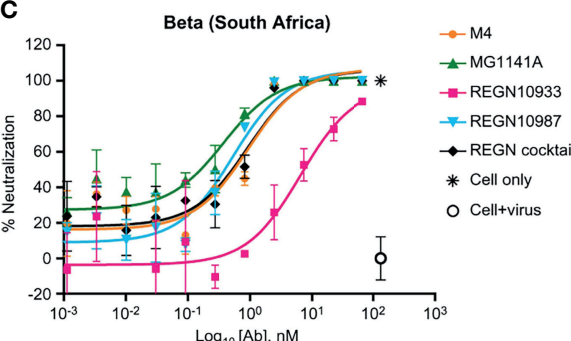

E

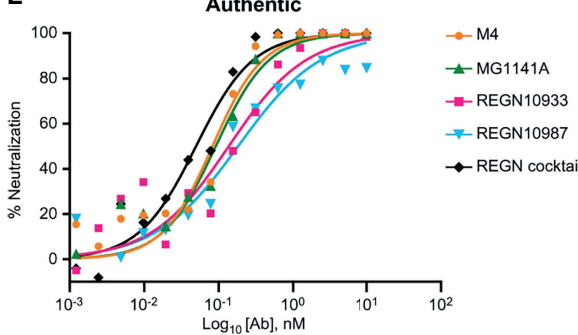

B

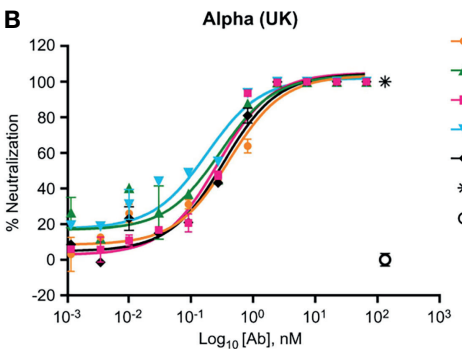

D

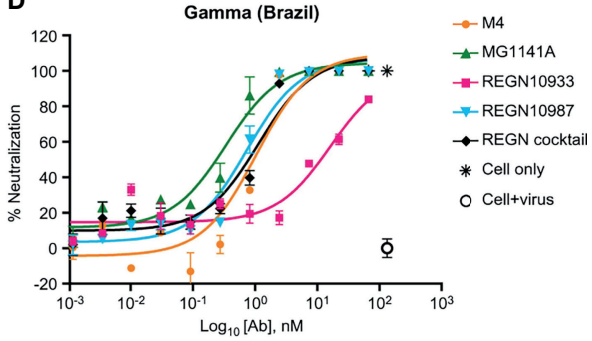

\begin{tabular}{|c|c|c|c|c|c|}
\hline $\mathrm{EC}_{50}$ (nM) & Authentic & WT & Alpha & Beta & Gamma \\
\hline $\mathrm{M} 4$ & 0.083 & 0.313 & 0.415 & 0.931 & 1.047 \\
\hline MG1141A & 0.092 & 0.249 & 0.295 & 0.372 & 0.340 \\
\hline REGN cocktail & 0.050 & 0.157 & 0.336 & 0.917 & 1.142 \\
\hline REGN10933 & 0.137 & 0.154 & 0.270 & 6.553 & 16.29 \\
\hline REGN10987 & 0.183 & 0.130 & 0.182 & 0.532 & 0.737 \\
\hline
\end{tabular}

FIGURE 3 | Neutralizing activity of anti-SARS-CoV-2 mAbs. (A-D) Dose-dependent neutralization of SARS-CoV-2 pseudovirus of D614G (wild type), Alpha (United Kingdom), Beta (South Africa), and Gamma (Brazil). Neutralizing activities of 11-point-diluted anti-SARS-CoV-2 mAbs were evaluated on ACE2-HEK293 cells using the luciferase assay system. The $\mathrm{EC}_{50}$ and $\mathrm{EC}_{90}$ values were determined by curve fitting with non-linear regression analysis (sigmoidal dose response). Bars, mean \pm standard error of the mean (SEM) of triplicates derived from one of the two experiments. (E) Dose-dependent neutralization of SARS-CoV-2 isolated from a patient (Korea/KUMC45/2020, GH clade) by mAbs, as evaluated by a plaque reduction neutralization test on Vero cells. One representative out of three experiments with similar results is shown. (F) The $\mathrm{EC}_{50}$ values of the in vitro neutralizing assay against variant viruses. 


\section{Epitope Binning of MG1141A}

Biolayer interferometry (BLI), a label-free detection system, was used for epitope binning of MG1141A. BLI, which can detect realtime competitive binding of antibodies, requires mAbs that have been identified as competitors. RBD-His was immobilized using an anti-penta-His biosensor, and the mAb was sequentially bound in an in-tandem manner. This allowed us to estimate the epitope of the new clone. To predict the epitope of MG1141A, three control antibodies with different epitopes were used: (1) REGN10933, which interacts with the ACE2 binding site, (2) REGN10987, which binds to an alternative ACE2 binding site; and (3) S309, which has an ACE2 non-binding site as an epitope different from those of previous Regeneron antibodies $(42,43)$. The epitope binning results showed that MG1141A competes with REGN10987 and S309. Against REGN10933, MG1141A showed intermediate competitive binding, whereas REGN10987 and S309 did not compete. Additionally, we determined the competitive binding of MG1141A and the ACE2 receptor to the target protein. Unlike S309, which did not compete with ACE2, MG1141A exhibited complete competition with ACE2. Overall, these results suggest that MG1141A exhibited full competition with the ACE2 receptor for binding to the target protein and possessed a significantly different epitope from those of the control Abs included in previous studies (Figure 5A and Supplementary Figure 6).

\section{Simulation Docking of MG1141A With RBD}

We performed homology antibody modeling and docking for the RBD of the viral S protein. BioLuminate suggested 15 models, and the first and second large clusters had 185 and 138 docking models, respectively. However, because the models from these clusters did not block the binding of ACE2, REGN10987, and S309 simultaneously, they were discarded. According to the binning results, MG1141A inhibited the binding of ACE2, REGN10987, and S309 to the target protein. The docking model from the third large cluster, which was 118 residues in size, was selected because it satisfied these criteria (Figure 5B). The sizes of the other clusters were less than 90 and did not satisfy these criteria. The selection criteria could be subjective; nevertheless, the docking model should be consistent with the binning results, and we believe our model is a suitable representation of the binning results. The residues of MG1141A did not interact with the mutated residues of the recently emerged variant viruses, except for Asn501Tyr. The mutation of Asn501 into Tyr501 did not have a negative effect on RBD binding because of the newly generated $\pi$ - $\pi$ interactions between Tyr56 and Tyr501. MG1141A did not bind to the SARSCoV-2 RBD (Figure 1). According to our model, the binding affinity of MG1141A to the RBD of SARS-CoV-2 may be reduced because of substitutions of Ser373 and Asn439 to Phe373 and Arg439 in the epitope region of SARS-CoV-2.

\section{DISCUSSION}

Antibody therapeutics against various viruses are being studied, and several antibodies have been approved for phase III clinical trials, including those that confer passive immunity to RSV (47, 48 ), reduce the mortality of Ebola virus infections (49), and reduce hospitalization in patients with COVID-19 infections. There are various methods for generating antibody candidates, such as from the blood of convalescent donors. An in vitro library using antibody genes from human B cells has also been constructed for this purpose. Approximately 10 years ago, procedures such as rapid isolation of antigen-positive B cells and immune profiling based on high-throughput sequencing were developed (50). These approaches, as well as versatile B cell repertoire analysis techniques, have been employed in the development of COVID-19 antibody therapeutics (51-53).

Humans produce antibodies specific to hyper-immunogenic regions of viral proteins or regions that effectively inhibit the binding of these proteins to human receptors. Viruses respond by introducing mutations in the regions against which human antibodies are formed to overcome the immune response or by evolving into strains that exhibit enhanced infection efficiency and survival (54-56). In the case of SARS-CoV-2, mutations in the nonstructure proteins coded by ORF1a and ORF1b occurred initially. Subsequently, S protein mutations such as D614G caused increased infectivity. N439K and N501Y mutations, which confer the capability of infectivity and immune evasion to SARS-CoV-2, were also detected in SARS-CoV-2. Most of the antibody therapeutics and vaccines currently being developed target $S$ proteins; thus, SARSCoV-2 can accelerate its evolution to escape human immune responses, thereby reducing the efficacy of SARS-CoV-2 treatments.
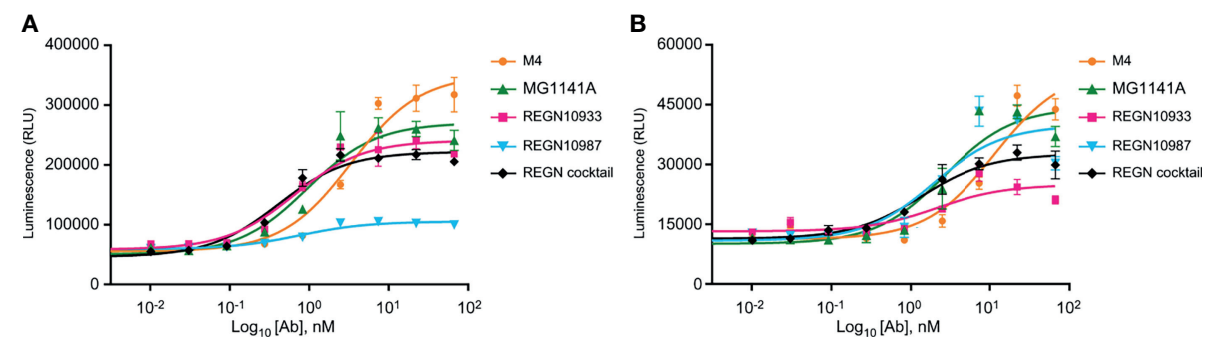

FIGURE 4 | Fc-mediated effector functions of anti-SARS-CoV-2 mAbs. (A) Activation of ADCC signaling was evaluated using a FcyRIIla-expressing reporter cell line as effector cells and SARS-CoV-2 S-glycoprotein-expressing HT1080 as target cells. (B) Activation of ADCP signaling was measured using FcyRlla-H-expressing reporter cell line as effector cells and SARS-CoV-2 S-glycoprotein-expressing HT1080 as target cells. In (A, B), bars are mean \pm standard error of the mean (SEM) of duplicates. 
A

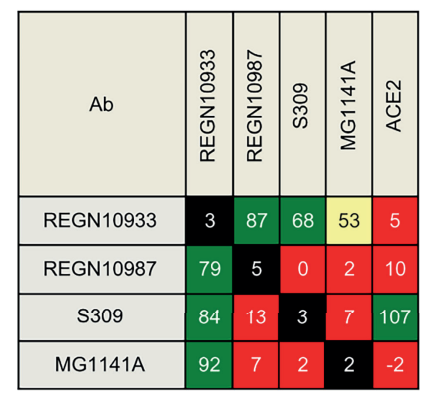

B

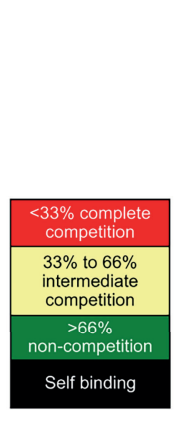

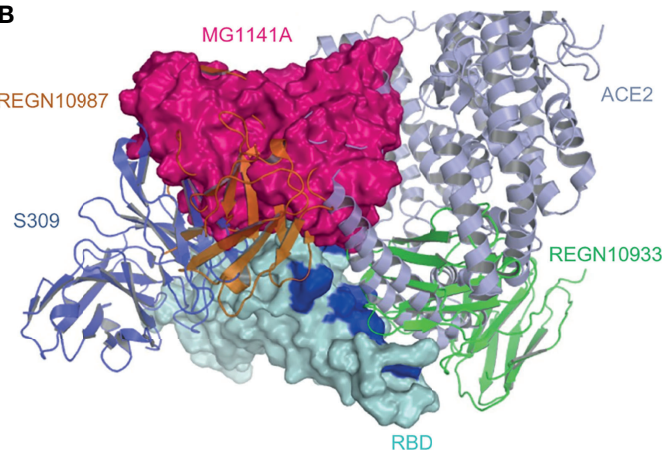

FIGURE 5 | Epitope binning of MG1141A. (A) Epitope binning heat map. Based on the reference binding, the binding level of the $2^{\text {nd }}$ antibody is shown in percentages (\%) and color. The $1^{\text {st }}$ binding antibody is shown in the row, while the $2^{\text {nd }}$ binding antibody is shown in the column. The diagonal lines in white indicate that the self-binding of $1^{\text {st }}$ and $2^{\text {nd }}$ binding antibodies is identical. (B) Superposition of MG1141A scFv docking model (hot pink) on RBD structures (cyan) complexed with REGN10987, REGN10933, and S309. MG1141A scFv collided with REGN10987 (orange), S309 (tv blue), and ACE2 (light blue), but not with REGN10933 (green). The ACE2binding region is represented by the blue color.

Our objective was to develop an antibody that can effectively neutralize the recently detected SARS-CoV-2 mutations and imminent mutations that may be potentially deleterious to human health. We generated the initial candidate antibodies through mouse immunization among various antibody screening methods. Currently, human antibodies are produced in transgenic mice using human antibody genes, which have been frequently used for mouse immune screening. REGN10933 (casirivimab) and REGN10987 (imdevimab), the COVID-19 antibodies produced by Regeneron Pharmaceuticals, are derived from transgenic mice (43). However, the source of antibody genes is the human antibody repertoire, providing these antibody candidates with the potential to reduce the severity of SARS-CoV-2 variant infections. Therefore, we decided to generate an initial candidate antibody by immunizing normal mice and then generating a final antibody through humanization. To generate an effective neutralizing antibody, the RBD, which is the ACE2-binding region of the S protein, was used as an antigen for mouse immunization. The stability of the RBD was enhanced by fusing it to the $\mathrm{Fc}$ region. Balb/c mice were immunized with RBD-Fc three times by intraperitoneal and intravenous injections. The scFv phage display library was constructed using the immune repertoire of immunized mice. The library was panned three times with the $\mathrm{S}$ protein coated on an immuno-tube. The obtained $\mathrm{scFv}$ clones were converted into human IgG1-kappa to produce an antiRBD chimeric IgG1 antibody, which were expressed in Expi293F cells. The $\mathrm{M} 4$ clones exhibited optimal $\mathrm{IC}_{50}$ values and were selected as initial candidates. The M4 sequence was identified using the mouse germline sequences IGHV5-6 and IGKV6-32. They showed high homology with human IGHV3-21 and IGKV3-15, and a humanized antibody was prepared through CDR grafting. We generated several humanized clones through CDR grafting, and an in vitro assay demonstrated that the abovementioned clone was the most efficacious (data not shown). In general, the binding affinity of the antibodies tended to decrease after humanization, but the $\mathrm{K}_{\mathrm{D}}$ value of MG1141A (M4 humanized clone) was maintained at $20 \mathrm{pM}$. The overall structure of the variable region of the humanized antibodies was not affected due to the high homology between the frameworks. Moreover, the core residues were preserved, and the affinity of the humanized antibodies was maintained by the canonical structure of the CDRs. For comparative analysis of its efficacy, REGN10933 and REGN10937 of Regeneron Pharmaceuticals, which are currently in phase III clinical trials, were used as controls. MG1141A exhibited an $\mathrm{IC}_{50}$ of $92 \mathrm{pM}$. This was equivalent to the neutralizing effect exhibited by REGN antibodies in authentic virus and pseudovirus neutralization assays. Furthermore, MG1141A induced both ADCC and ADCP, similar to REGN. As a result, MG1141 A showed equivalent in vitro potency as a single monoclonal antibody, compared with the REGN cocktail. Furthermore, it binds to a different epitope and may serve as a novel antibody therapeutic agent.

We also generated human monoclonal antibodies from the blood of the COVID-19 convalescent donors. The blood samples were collected within 1 month of recovery from 19 donors who were infected with COVID-19 between March and May 2020 (IRB number: YUMC 2020-04-009). For donor screening, antibody titers in the blood were measured by ELISA against the $S$ protein ECD and RBD, and the PRNT test was performed on the authentic virus (Supplementary Figure 7). Among the 19 donors, the $\mathrm{B}$ cell repertoire gene was obtained from memory $\mathrm{B}$ cells from 8 donors who showed a high antibody titer and neutralizing effect to construct a phage display library. The phage display library screening was performed as described in this manuscript. A total of 99 unique antibody sequences were generated, of which 28 clones showing high binding were purified with IgG1 to assess the affinity and neutralizing effect. Fully human monoclonal antibodies bound to the $S$ protein ECD at sub-nM to single-digit $\mathrm{nM}$ levels, but there were five clones that specifically bound to the RBD. Eight clones confirmed neutralizing efficacy at the level of double- to triple-digit $\mathrm{nM}$ against authentic virus (Supplementary Table 2). We compared the efficacy of fully human monoclonal antibodies and M4 clones and confirmed that M4 had the best efficacy. Regeneron also proceeded to generate antibodies from the mouse immune 
method and the blood of the convalescent donors. The antibody pool generated through mouse immunization was superior to the antibody pool from humans, and as such, casirivimab and imdevimab could be generated through mouse immunization (41). The method of generating antibodies from convalescent donors has the advantage generating antibodies against SARSCoV-2 most quickly; therefore, it was used in the early stages of the development of COVID-19 antibody therapeutics. However, because the production of antibodies by immune response after SAR-CoV-2 infection in humans occurs in many hyperimmunogenic sites of the $\mathrm{S}$ protein $\mathrm{ECD}$, it was not easy to find effective neutralizing antibodies because only a few bind specifically to the RBM. In the case of RSV and influenza, because infections can occur several times over the human lifespan, many effective neutralizing antibodies can be generated, but in the case of single-time infections such as SARS-CoV-2, designing RBD antigens to bind specifically to the $\mathrm{RBM}$ and generating antibodies through mouse immunization is considered to be one way to generate more effective neutralizing antibodies than fully human antibodies from convalescent human donors.

\section{DATA AVAILABILITY STATEMENT}

The original contributions presented in the study are included in the article/Supplementary Material. Further inquiries can be directed to the corresponding author.

\section{ETHICS STATEMENT}

The animal study was reviewed and approved by Institutional Animal Care and Use Committee of GC Pharma. The collection

\section{REFERENCES}

1. Wang C, Wang Z, Wang G, Lau JY-N, Zhang K, Li W. COVID-19 in Early 2021: Current Status and Looking Forward. Signal Transduct Target Ther (2021) 6:114. doi: 10.1038/s41392-021-00527-1

2. Wan Y, Shang J, Graham R, Baric RS, Li F. Receptor Recognition by the Novel Coronavirus From Wuhan: An Analysis Based on Decade-Long Structural Studies of SARS Coronavirus. J Virol (2020) 94:e00127-20. doi: 10.1128/ JVI.00127-20

3. Shang J, Wan Y, Luo C, Ye G, Geng Q, Auerbachet A, et al. Cell Entry Mechanisms of SARS-CoV-2. Proc Natl Acad Sci USA (2020) 117:11727-34. doi: 10.1073/pnas.2003138117

4. Lan J, Ge J, Yu J, Shan S, Zhou H, Fan S, et al. Structure of the SARS-CoV-2 Spike Receptor-Binding Domain Bound to the ACE2 Receptor. Nature (2020) 581:215-20. doi: 10.1038/s41586-020-2180-5

5. Chen P, Nirula A, Heller B, Gottlieb RL, Boscia J, Morris J, et al. SARS-CoV-2 Neutralizing Antibody LY-Cov555 in Outpatients With Covid-19. N Engl J Med (2021) 384:229-37. doi: 10.1056/NEJMoa2029849

6. Ledford H. COVID Antibody Treatments Show Promise for Preventing Severe Disease. Nature (2021) 591:513-4. doi: 10.1038/d41586-021-00650-7

7. Weinreich DM, Sivapalasingam S, Norton T, Ali S, Gao H, Bhore R, et al. REGN-COV2, a Neutralizing Antibody Cocktail, in Outpatients With Covid19. N Engl J Med (2021) 384:238-51. doi: 10.1056/NEJMoa2035002

8. Yasui F, Kohara M, Kitabatake M, Nishiwaki T, Fujii H, Tateno C, et al. Phagocytic Cells Contribute to the Antibody-Mediated Elimination of of convalescent human blood was reviewed and approved by Institutional Review Board of Yeungnam University.

\section{AUTHOR CONTRIBUTIONS}

SL, SJ, and D-SK conceived and designed the project. SL, SJ, JKa, SP, YH, HN, MK, JL, JKi, MO, JR, JS, YK, and D-SK performed and designed experiments. YH, JL, M-SP, Y-SK, HP, and D-SK provided advice on experimental design and data analysis. SL, SJ, $\mathrm{HN}, \mathrm{MK}, \mathrm{KC}, \mathrm{JKi}$, and D-SK wrote the manuscript. All authors contributed to the article and approved the submitted version.

\section{FUNDING}

This research was supported by the Mogam Institute for Biomedical Research and GC Pharma, Republic of Korea (Grant number: MG1141A). The funder was not involved in the study design, collection, analysis, interpretation of data, the writing of this article or the decision to submit it for publication.

\section{ACKNOWLEDGMENTS}

The authors would like to thank Prof. J. McLellan and Prof. Chang-Han Lee for providing the RBD- and ACE2expressing plasmids.

\section{SUPPLEMENTARY MATERIAL}

The Supplementary Material for this article can be found online at: https://www.frontiersin.org/articles/10.3389/fimmu.2021. 778829/full\#supplementary-material

Pulmonary-Infected SARS Coronavirus. Virology (2014) 454-455:157-68. doi: 10.1016/j.virol.2014.02.005

9. He W, Chen C-J, Mullarkey CE, Hamilton JR, Wong CK, Leon PE, et al. Alveolar Macrophages are Critical for Broadly-Reactive Antibody-Mediated Protection Against Influenza a Virus in Mice. Nat Commun (2017) 8:846. doi: 10.1038/s41467-017-00928-3

10. Taylor PC, Adams AC, Hufford MM, de la Torre I, Winthrop K, Gottlieb RL. Neutralizing Monoclonal Antibodies for Treatment of COVID-19. Nat Rev Immunol (2021) 21:382-93. doi: 10.1038/s41577-021-00542-X

11. Yurkovetskiy L, Wang X, Pascal KP, Tomkins-Tinch C, Nyalile TP, Wang Y. Structural and Functional Analysis of the D614G SARS-CoV-2 Spike Protein Variant. Cell (2020) 183:739-51.e8. doi: 10.1016/j.cell.2020.09.032

12. Mansbach RA, Chakraborty S, Nguyen K, Montefiori DC, Korber B, Gnanakaran S. The SARS-CoV-2 Spike Variant D614G Favors an Open Conformational State. Sci Adv (2021) 7:eabf3671. doi: 10.1126/sciadv.abf3671

13. Ozono S, Zhang Y, Ode H, Sano K, Tan TS, Imai K, et al. SARS-CoV-2 D614G Spike Mutation Increases Entry Efficiency With Enhanced ACE2-Binding Affinity. Nat Commun (2021) 12:848. doi: 10.1038/s41467-021-21118-2

14. Hou YJ, Chiba S, Halfmann P, Ehre C, Kuroda M, Dinnon KH, et al. SARS-CoV-2 D614G Variant Exhibits Efficient Replication Ex Vivo and Transmission in Vivo. Science (2020) 370:1464-8. doi: 10.1126/science.abe8499

15. Korber B, Fischer WM, Gnanakaran S, Yoon H, Theiler J, Abfalterer W, et al. Tracking Changes in SARS-CoV-2 Spike: Evidence That D614G Increases Infectivity of the COVID-19 Virus. Cell (2020) 182:812-27.e19. doi: 10.1016/ j.cell.2020.06.043 
16. Lee CY, Amrun SN, Chee RS-L, Goh YS, Mak T-M, Octavia S, et al. Human Neutralising Antibodies Elicited by SARS-CoV-2 non-D614G Variants Offer Cross-Protection Against the SARS-CoV-2 D614G Variant. Clin Transl Immunol (2021) 10:e1241. doi: 10.1002/cti2.1241

17. Meng B, Kemp SA, Papa G, Datir R, ATM Ferreira I, Marelli S, et al. Recurrent Emergence of SARS-CoV-2 Spike Deletion H69/V70 and its Role in the Alpha Variant B.1.1.7. Cell Rep (2021) 35:109292. doi: 10.1016/j.celrep.2021.109292

18. Naveca F, Nascimento V, Souza V, Corado A, Nascimento F, Silva G, et al. Phylogenetic Relationship of SARS-CoV-2 Sequences From Amazonas With Emerging Brazilian Variants Harboring Mutations in the Spike Protein. Virol Org (2021), E484k and N501y.

19. Gan HH, Twaddle A, Marchand B, Gunsalus KC. Structural Modeling of the SARS-CoV-2 Spike/Human ACE2 Complex Interface can Identify HighAffinity Variants Associated With Increased Transmissibility. J Mol Biol (2021) 433:167051. doi: 10.1016/j.jmb.2021.167051

20. Supasa P, Zhou D, Dejnirattisai W, Liu C, Mentzer AJ, Ginn HM, et al. Reduced Neutralization of SARS-CoV-2 B.1.1.7 Variant by Convalescent and Vaccine Sera. Cell (2021) 184:2201-11.e7. doi: 10.1016/j.cell.2021.02.033

21. Nelson G, Buzko O, Spilman P, Niazi K, Rabizadeh S, Soon-Shiong P. Molecular Dynamic Simulation Reveals E484K Mutation Enhances Spike RBD-ACE2 Affinity and the Combination of E484K K417n and N501y Mutations (501Y. V2 Variant) Induces Conformational Change Greater Than N501Y Mutant Alone, Potentially Resulting in an Escape Mutant. BioRxiv (2021). doi: 10.1101/2021.01.13.426558

22. Wang P, Casner RG, Nair MS, Wang M, Yu J, Cerutti G, et al. Increased Resistance of SARS-CoV-2 Variant P.1 to Antibody Neutralization. Cell Host Microbe (2021) 29:747-51.e4. doi: 10.1016/j.chom.2021.04.007

23. Kuzmina A, Khalaila Y, Voloshin O, Keren-Naus A, Boehm-Cohen L, Raviv Y, et al. SARS-CoV-2 Spike Variants Exhibit Differential Infectivity and Neutralization Resistance to Convalescent or Post-Vaccination Sera. Cell Host Microbe (2021) 29:522-8.e2. doi: 10.1016/j.chom.2021.03.008

24. Zhou D, Dejnirattisai W, Supasa P, Liu C, Mentzer AJ, Ginn HM, et al. Evidence of Escape of SARS-CoV-2 Variant B.1.351 From Natural and Vaccine-Induced Sera. Cell (2021) 184:2348-61.e6. doi: 10.1016/j.cell.2021.02.037

25. Gandhi RT, Lynch JB, Del Rio C. Mild or Moderate Covid-19. N Engl J Med (2020) 383:1757-66. doi: 10.1056/NEJMcp2009249

26. ACTIV-3/TICO LY-CoV555 Study Group. A Neutralizing Monoclonal Antibody for Hospitalized Patients With Covid-19. N Engl J Med (2021) 384:905-14. doi: 10.1056/NEJMoa2033130

27. Wang Y, Liu L. The Membrane Protein of Severe Acute Respiratory Syndrome Coronavirus Functions as a Novel Cytosolic Pathogen-Associated Molecular Pattern to Promote Beta Interferon Induction via a Toll-Like-ReceptorRelated TRAF3-Independent Mechanism. mBio (2016) 7:e01872-15. doi: 10.1128/mBio.01872-15

28. Patra T, Meyer K, Geerling L, Isbell TS, Hoft DF, Brien J, et al. SARS-CoV-2 Spike Protein Promotes IL-6 Trans-Signaling by Activation of Angiotensin II Receptor Signaling in Epithelial Cells. PloS Pathog (2020) 16:e1009128. doi: 10.1371/journal.ppat.1009128

29. Iwasaki M, Saito J, Zhao H, Sakamoto A, Hirota K, Ma D. Inflammation Triggered by SARS-CoV-2 and ACE2 Augment Drives Multiple Organ Failure of Severe COVID-19: Molecular Mechanisms and Implications. Inflammation (2021) 44:13-34. doi: 10.1007/s10753-020-01337-3

30. Wrapp D, Wang N, Corbett KS, Goldsmith JA, Hsieh C-L, Abiona O, et al. Cryo-EM Structure of the 2019-Ncov Spike in the Prefusion Conformation. Science (2020) 367:1260-3. doi: 10.1126/science.abb2507

31. Bradbury A. Antibody Engineering. Berlin: Springer (2010). p. 15-20.

32. Schaefer JV, Honegger A, Plückthun A. Antibody Engineering. Berlin: Springer (2010). p. 21-44.

33. Zhu K, Day T, Warshaviak D, Murrett C, Friesner R. Pearlman D Antibody Structure Determination Using a Combination of Homology Modeling, Energy-Based Refinement, and Loop Prediction. Proteins (2014) 82:164655. doi: 10.1002/prot.24551

34. Kozakov D, Brenke R, Comeau SR, Vajda S. PIPER: An FFT-Based Protein Docking Program With Pairwise Potentials. Proteins (2006) 65:392-406. doi: $10.1002 /$ prot.21117

35. Jones PT, Dear PH, Foote J, Neuberger MS, Winter G. Replacing the Complementarity-Determining Regions in a Human Antibody With Those From a Mouse. Nature (1986) 321:522-5. doi: 10.1038/321522a0
36. Kim DS, Lee S-H, Kim J-S, Lee S-C, Kwon M-H, Kim Y-S. Generation of Humanized Anti-DNA Hydrolyzing Catalytic Antibodies by Complementarity Determining Region Grafting. Biochem Biophys Res Commun (2009) 379:314-8. doi: 10.1016/j.bbrc.2008.12.051

37. Glanville J, Zhai W, Berka J, Telman D, Huerta G, Mehta GR, et al. Precise Determination of the Diversity of a Combinatorial Antibody Library Gives Insight Into the Human Immunoglobulin Repertoire. Proc Natl Acad Sci USA (2009) 106:20216-21. doi: 10.1073/pnas.0909775106

38. Tiller T, Schuster I, Deppe D, Siegers K, Strohner R, Herrmann T, et al. A Fully Synthetic Human Fab Antibody Library Based on Fixed VH/VL Framework Pairings With Favorable Biophysical Properties. mAbs (2013) 5:445-70. doi: $10.4161 / \mathrm{mabs} .24218$

39. Ewert S, Huber T, Honegger A, Plückthun A. Biophysical Properties of Human Antibody Variable Domains. J Mol Biol (2003) 325:531-53. doi: 10.1016/s0022-2836(02)01237-8

40. Ewert S, Honegger A, Plückthun A. Stability Improvement of Antibodies for Extracellular and Intracellular Applications: CDR Grafting to Stable Frameworks and Structure-Based Framework Engineering. Methods (2004) 34:184-99. doi: 10.1016/j.ymeth.2004.04.007

41. Baum A, Fulton BO, Wloga E, Copin R, Pascal KE, Russo V, et al. Antibody Cocktail to SARS-CoV-2 Spike Protein Prevents Rapid Mutational Escape Seen With Individual Antibodies. Science (2020) 369:1014-8. doi: 10.1126/ science.abd0831

42. Pinto D, Park Y-J, Beltramello M, Walls AC, Tortorici MA, Bianchi S, et al. Cross-Neutralization of SARS-CoV-2 by a Human Monoclonal SARS-CoV Antibody. Nature (2020) 583:290-5. doi: 10.1038/s41586-020-2349-y

43. Hansen J, Baum A, Pascal KE, Russo V, Giordano S, Wloga E, et al. Studies in Humanized Mice and Convalescent Humans Yield a SARS-CoV-2 Antibody Cocktail. Science (2020) 369:1010-14. doi: 10.1126/science.abd0827

44. Leon PE, He W, Mullarkey CE, Bailey MJ, Miller MS, Krammer F, et al. Optimal Activation of Fc-Mediated Effector Functions by Influenza Virus Hemagglutinin Antibodies Requires Two Points of Contact. Proc Natl Acad Sci USA (2016) 113:E5944-51. doi: 10.1073/pnas.1613225113

45. Gunn BM, Yu W-H, Karim MM, Brannan JM, Herbert AS, Wec AZ, et al. A Role for Fc Function in Therapeutic Monoclonal Antibody-Mediated Protection Against Ebola Virus. Cell Host Microbe (2018) 24:221-33.e5. doi: 10.1016/j.chom.2018.07.009

46. Asokan M, Dias J, Liu C, Maximova A, Ernste K, Pegu A, et al. Fc-Mediated Effector Function Contributes to the in Vivo Antiviral Effect of an HIV Neutralizing Antibody. Proc Natl Acad Sci USA (2020) 117:18754-63. doi: 10.1073/pnas.2008236117

47. Griffin MP, Yuan Y, Takas T, Domachowske JB, Madhi SA, Manzoni P, et al. Single-Dose Nirsevimab for Prevention of RSV in Preterm Infants. $N$ Engl J Med (2020) 383:415-25. doi: 10.1056/NEJMoa1913556

48. Pollack P, Groothuis JR. Development and Use of Palivizumab (Synagis): A Passive Immunoprophylactic Agent for RSV. J Infect Chemother (2002) 8:201-6. doi: 10.1007/s10156-002-0178-6

49. Mulangu S, Dodd LE, Davey RT Jr, Mbaya OT, Proschan M, Mukadi D, et al. A Randomized, Controlled Trial of Ebola Virus Disease Therapeutics. N Engl J Med (2019) 381:2293-303. doi: 10.1056/NEJMoa1910993

50. Wu X, Zhou T, Zhu J, Zhang B, Georgiev I, Wang C, et al. Focused Evolution of HIV-1 Neutralizing Antibodies Revealed by Structures and Deep Sequencing. Science (2011) 333:1593-602. doi: 10.1126/science.1207532

51. Gilman MS, Castellanos CA, Chen M, Ngwuta JO, Goodwin E, Moin SM, et al. Rapid Profiling of RSV Antibody Repertoires From the Memory B Cells of Naturally Infected Adult Donors. Sci Immunol (2016) 1:eaaj1879. doi: 10.1126/sciimmunol.aaj1879

52. Goodwin E, Gilman MSA, Wrapp D, Chen M, Ngwuta JO, Moin SM, et al. Infants Infected With Respiratory Syncytial Virus Generate Potent Neutralizing Antibodies That Lack Somatic Hypermutation. Immunity (2018) 48:339-49.e5. doi: 10.1016/j.immuni.2018.01.005

53. Zost SJ, Gilchuk P, Chen RE, Case JB, Reidy JX, Trivette A, et al. Rapid Isolation and Profiling of a Diverse Panel of Human Monoclonal Antibodies Targeting the SARS-CoV-2 Spike Protein. Nat Med (2020) 26:1422-7. doi: 10.1038/s41591-020-0998-x

54. Andreano E, Rappuoli R. SARS-CoV-2 Escaped Natural Immunity, Raising Questions About Vaccines and Therapies. Nat Med (2021) 27:759-61. doi: 10.1038/s41591-021-01347-0 
55. Burioni R, Topol EJ. Assessing the Human Immune Response to SARS-CoV-2 Variants. Nat Med (2021) 27:571-2. doi: 10.1038/s41591-021-01290-0

56. Eguia RT, Crawford KHD, Stevens-Ayers T, Kelnhofer-Millevolte L, Greninger AL, Englund JA, et al. A Human Coronavirus Evolves Antigenically to Escape Antibody Immunity. PloS Pathog (2021) 17: e1009453. doi: 10.1371/journal.ppat.1009453

Conflict of Interest: SL, SJ, JKa, SP, YH, HN, MK, JL, KC, MO, JR, JL, and D-SK submitted a patent application on neutralizing antibodies against SARS-CoV-2.

The remaining authors declare that the research was conducted in the absence of any commercial or financial relationships that could be construed as a potential conflict of interest.
Publisher's Note: All claims expressed in this article are solely those of the authors and do not necessarily represent those of their affiliated organizations, or those of the publisher, the editors and the reviewers. Any product that may be evaluated in this article, or claim that may be made by its manufacturer, is not guaranteed or endorsed by the publisher.

Copyright $\odot 2021$ Lee, Jang, Kang, Park, Han, Nam, Kim, Lee, Cho, Kim, Oh, Ryu, Seok, Kim, Lee, Park, Kim, Park and Kim. This is an open-access article distributed under the terms of the Creative Commons Attribution License (CC BY). The use, distribution or reproduction in other forums is permitted, provided the original author(s) and the copyright owner(s) are credited and that the original publication in this journal is cited, in accordance with accepted academic practice. No use, distribution or reproduction is permitted which does not comply with these terms. 